\title{
Adapted tool for the assessment of domestic violence against women in a low-income country setting: a reliability analysis
}

This article was published in the following Dove Medical Press journal: International Journal of Women's Health

\author{
Agumasie Semahegn ${ }^{1,2}$ \\ Kwasi Torpey' \\ Abubakar Manu' \\ Nega Assefa ${ }^{2}$ \\ Augustine Ankomah ${ }^{1,3}$ \\ 'Department of Population, Family \\ and Reproductive Health, School \\ of Public Health, College of Health \\ Science, University of Ghana, Legon, \\ Accra, Ghana; ${ }^{2}$ School of Nursing \\ and Midwifery, College of Health \\ and Medical Sciences, Haramaya \\ University, Harar, Ethiopia; ${ }^{3}$ Population \\ Council, Accra, Ghana
}

Background: One-in-three women has experienced domestic violence, which is a serious public health problem and a human right violation. Domestic violence is a common life experience among women in Ethiopia. The tool used to assess violence against women (VAW) has not been validated to assess its consistency. Cronbach's alpha ( $\alpha$, or coefficient alpha) is a measure of internal consistency, or reliability, that is, how closely a set of items are related as a group. Reliability is how well a test measures what it should. Therefore, the aim of this study was to estimate the inter-item correlation (reliability) of the tool adapted from literature.

Methods: A community-based study was conducted in Northwestern Ethiopia between November 15, 2017 and December 31, 2017. A total of 1,269 women at their permanent place of residence (specifically at their households) were recruited using the multistage stratified systematic sampling method. A structured questionnaire was adapted from literature. Also, 12 trained female data collectors collected the data using the face-to-face interview method. Data were entered into EpiData 3.1.0 and exported to SPSS 23.0 for analysis. Descriptive statistical analysis was carried out to estimate the reliability of the response(s).

Results: Overall, Cronbach's alpha was higher than the minimum recommended value of 0.70 . Cronbach's alpha for specific sections were 0.764 for women's decision-making autonomy (13 items); women's accepting attitude toward justified wife-beating (five items, 0.894); physical violence (seven items, 0.876); psychological violence (15 items, 0.925); sexual violence (five items, 0.812); and inequitable gender-norms (seven items, 0.867).

Conclusion: The tool used to assess domestic VAW in Northwestern Ethiopia had a high reliability. Therefore, researchers can adapt the tool and further assess its reliability in other settings to have a common and validated tool to study VAW in a low-income countries.

Keywords: violence against women, tool reliability analysis, low-income countries

\section{Introduction}

Violence against women (VAW) is a global public health pandemic and a serious human rights violation. Worldwide, one-in-three women has experienced VAW. ${ }^{1-8}$ Domestic VAW is a common experience in the lives of women in Ethiopia. A World Health Organization's (WHO's) multi-country study indicated that domestic VAW in Ethiopia was $71 \%$, which is the highest in the world. ${ }^{9}$ A systematic review conducted in Ethiopia (2000-2014) indicated that domestic VAW is a common phenomenon ranging from $20 \%$ to $78 \%{ }^{10}$ Women's favorable attitude toward justifiable wifebeating, exacerbated by traditional gender-norms is a key underlying factor explaining domestic VAW. Currently, women's receptive attitude toward justified wife-beating has declined from $81 \%{ }^{11}$ to $69 \% ;^{12}$ however, this is still unacceptably high.
Correspondence: Agumasie Semahegn School of Nursing and Midwifery, College of Health and Medical Sciences, Haramaya University, PO Box 235, Harar, Ethiopia Tel +25I 91 3359717

Email agumas04@gmail.com 
In response to the high prevalence of domestic VAW, the government of Ethiopia has incorporated women's right and gender equality in the constitution [Art-35 and $89(7)^{13}$ and other proclamations: Criminal code under proclamation No 414/2004 (Art 564) ${ }^{14}$ and Family Code Proclamation No 213/2000]. ${ }^{15}$ Violence against a marriage partner or a person cohabiting, even in an irregular union, is prohibited. Moreover to help implement this, the Ethiopian Ministry of Health has developed a standard operating procedure for the response and prevention of VAW in 2016. ${ }^{16}$ Most of the studies on domestic VAW that have been conducted in Ethiopia, like ours, have adapted tools from existing literature, including the WHO's domestic VAW assessment tool. ${ }^{13,16-34}$

Cronbach's alpha ( $\alpha$, or coefficient alpha) is a measure of internal consistency, or reliability, that is, how closely a set of items are related as a group. Cronbach's alpha is developed by Lee Cronbach in 1951, which measures reliability of the tool. Reliability is how well a test measures what it should. ${ }^{17,18} \mathrm{~A}$ review of all the studies showed that the level of Cronbach's alpha of the domestic VAW assessment tools is not reported in most of the studies, which have been conducted in low-income countries (particularly Ethiopia). The consistency of the items of domestic VAW assessment tool is a core component of the studies, and Cronbach's alpha is not estimated and reported. We could not find a literature that reported the reliability (Cronbach's alpha) estimates of the domestic VAW assessment tool. Hence, the main objective of this study was to estimate the inter-item-correlation (reliability) of the tool adapted from any literature on domestic VAW in low-income country settings. This study tool was adapted from literature to assess the level of domestic VAW in the Northwestern Ethiopia. Therefore, this study may contribute to filling the literature gap of reliability estimates of tools that often used to assess domestic VAW.

\section{Methods}

\section{Study design and setting}

A community-based cross-sectional study was conducted in the Awi zone of Northwestern Ethiopia from November 15, 2017 to December 31, 2017. This was to serve as a baseline survey for a three-arm quasi-experimental study. Awi zone has nine districts, of which three districts were included in the study. It is located $447 \mathrm{~km}$ from Addis Ababa. According to the Awi zonal health department report published in June 2018 , this zone has a total population of $1,285,242$, of whom $631,054(49.1 \%)$ are men and 654,188 (50.9\%) are women. About $12.5 \%$ of the population in Awi zone live in urban areas. Almost $93.5 \%$ of the population are Ethiopian Orthodox
Christian while $5.4 \%$ of the population are Muslim. ${ }^{11}$ Very little is known about domestic VAW in Awi zone, but one study shows the level of VAW to be as high as $78.0 \% .^{13}$

\section{Sample size determination and sampling procedures}

Sample size was calculated using a statistical formula ${ }^{19}$ with $5 \%$ margin of error, $95 \%$ significance level, $80 \%$ power, desired intervention effect of $13 \%$, and design effect of $1.11 .{ }^{12}$ Eventually, the final sample size was 1,269 married or cohabitating women (15-49 years). Married or cohabitating women (15-49 years) who had lived at least 12 months with their current husband and lived at least 6 months in the selected subdistricts were eligible. Three out of nine districts were selected randomly in the Awi zone by a lottery method. Then two (urban and rural) sub-districts were selected purposefully considering their appropriateness, resource, time, and geographical nonproximity to reduce threats to validity arising from possible information contamination. Sampling frame was constructed from the health extension workers' household registry (family-folder) to recruit eligible women from each selected sub-district. Multistage, stratified, and systematic sampling methods were used to recruit women at their permanent places of residence. The first household (random start) was recruited by lottery method using the first eligible household numbers ( 1 to kth value =2). In the case of two eligible women being present in a single household, one woman was selected for the interview using the lottery method (Figure 1). For further details, the protocol has been registered (ClinicalTrials.gov ID: NCT03265626) and published elsewhere. ${ }^{20}$

The protocol was reviewed and approved by the Institutional Health Research Ethical Review Committee, College of Health and Medical Sciences, Haramaya University (Ref. No IHRERC/146/2017). This study was conducted in accordance with the Declaration of Helsinki, ${ }^{21}$ and written informed consent was obtained from each study participant (woman), and the information was kept confidential and anonymous. Confidentiality of the information was maintained, among others by avoiding personal identifiers, locking the metallic cabinet for hardcopy questionnaire and investigators placing password on computers with stored data. Participant's deidentified data that support the analysis finding of this study as well as further analysis works will be shared as per official and valid request to the corresponding author (AS). Participant deidentified data will also be available online in the protocol registration database (ClinicalTrials.gov ID: NCT03265626), and also this journal web-pages as necessary as soon as further analysis for additional manuscripts is 


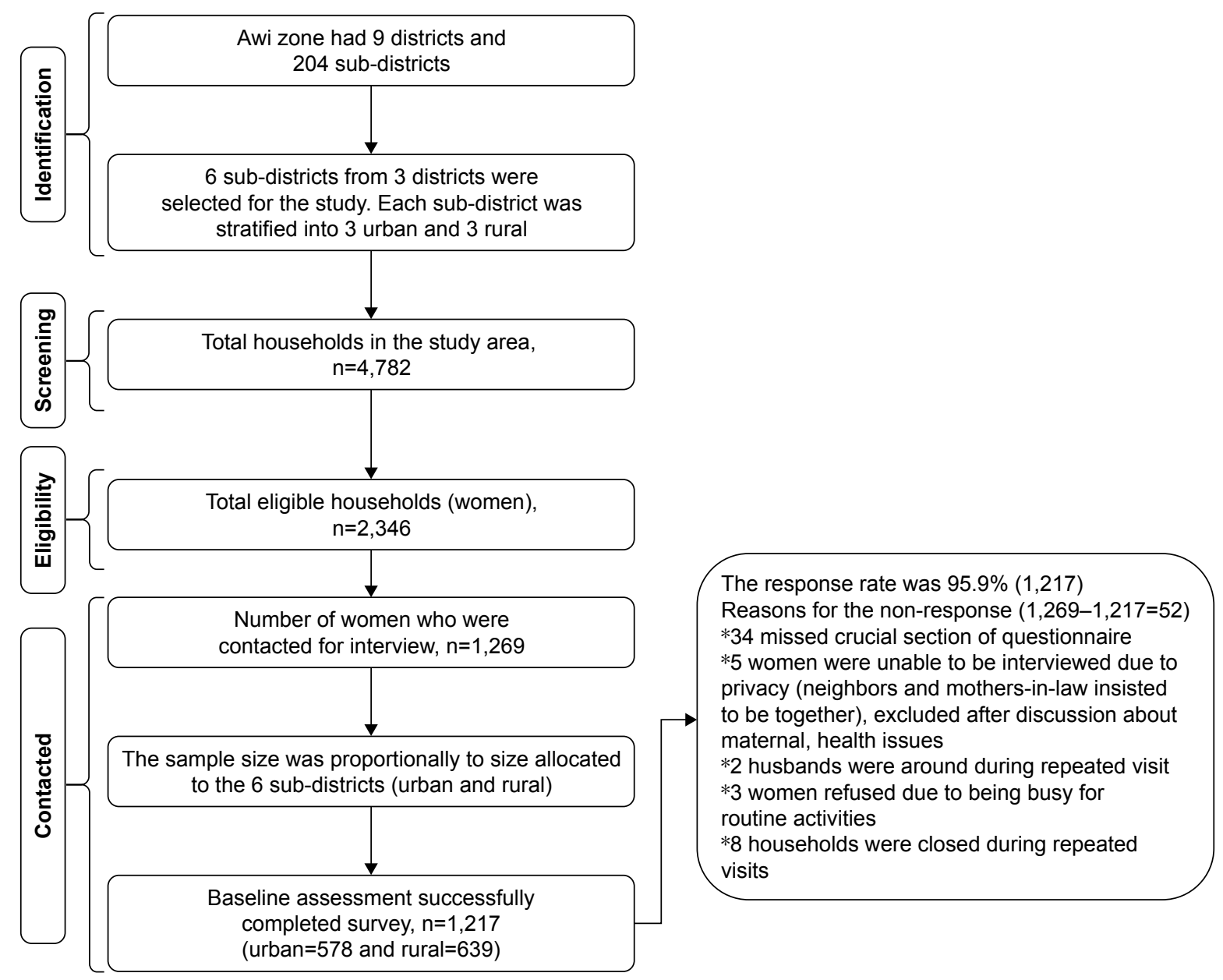

Figure I Illustration of participant recruitment process.

completed on SPSS (23.0) software after May 2019. In addition, ethical approval letter is available at any time.

\section{Tool development and data collection methods}

The data collection tool was adapted from several source in the literature ${ }^{13,16-34}$ (Table 1). Face-to-face intervieweradministered method was carried out using the structured questionnaire administered by the 12 trained female data collectors. Data collectors' training, pretest, and supportive supervision were provided by the principal investigator to assure the quality of data collected. Qualified female professionals (midwives, nurses, or public health workers) who have experience in field surveys and were neither resident nor deployed at nearby health facilities were hired as data collectors in order to increase the trustworthiness of the information. The training of data collectors was focused on the questionnaires, interview techniques, sampling methods, protection of confidentiality, ethical issues of domestic VAW research, and data quality assurance. Necessary amendments were made based on feedback from study participants and comments from data collectors.

\section{Data processing and analysis}

Overall, the domestic VAW assessment tool comprised nine sections. Three of the sections were sociodemographic and economic characteristics of women; access to sources of information about VAW and gender equality; and their husbands' sociodemographic characteristics. The latter was not included in the reliability analysis. Six of the sections that covered the women's decision-making potential and women's access to household resources and control over autonomy (13 items) ${ }^{35}$ women's accepting attitude toward justified wife-beating (five items), ${ }^{28,36}$ physical violence (seven items), psychological violence (15 items), sexual violence (five items), ${ }^{37,38}$ and gender inequitable norm (seven items). ${ }^{23}$ The reliability analysis was carried out for the six sections of the tool. The gathered data were entered into 
Table I Adapted tool to measure domestic violence against women in a low-income country setting

\begin{tabular}{|c|c|c|}
\hline & Items & Outcome \\
\hline \multicolumn{2}{|c|}{$\begin{array}{l}\text { Women's decision-making autonomy on household matters (WDMAQ) ( } 1 \text { - husband, } \\
2 \text { - wife, and } 3 \text { - joint) }\end{array}$} & \\
\hline WDMAQI & Who is the head of the household? & \\
\hline WDMAQ2 & Who should decide on the household matters in your family? & \\
\hline WDMAQ3 & Who makes large household purchases? & \\
\hline WDMAQ4 & Who makes small daily household purchases? & \\
\hline WDMAQ5 & Who is the decision maker when you want to visit family, friends, or relatives? & \\
\hline WDMAQ6 & Who is the decision maker on contraceptive to have planned family service? & \\
\hline WDMAQ7 & Who is the decision maker on antenatal care service utilization? & \\
\hline WDMAQ8 & Who is the decision maker on vaccination service utilization? & \\
\hline WDMAQ9 & Do you discuss about family planning with your husband? & \\
\hline WDMAQI0 & Who in your family makes decisions about health care for yourself? & \\
\hline WDMAQII & $\begin{array}{l}\text { Do you have an autonomy to decide by yourself and go to health care facility to } \\
\text { seek care for you and your children? }\end{array}$ & \\
\hline WDMAQI2 & Who is the decision maker to seek health care when one of family member get sick? & \\
\hline WDMAQI3 & Who is the decision maker if you want to attend workshop? & \\
\hline \multicolumn{2}{|c|}{ Measures for gender inequity norms index assessment (GINQ) (yes/no) } & \\
\hline GINQI & Is it fine for men to have more than one (sexual) partner? & \\
\hline GINQ2 & $\begin{array}{l}\text { Is it a woman's duty to have sex with her spouse/partner even if she } \\
\text { does not want to have? }\end{array}$ & \\
\hline GINQ3 & $\begin{array}{l}\text { Is it more important for a woman to respect her spouse/partner than it is for a man } \\
\text { to respect his spouse/partner? }\end{array}$ & $\begin{array}{l}\text { de } \\
\text { able }\end{array}$ \\
\hline GINQ4 & May a man beat his spouse/partner if she disobeys him? & \\
\hline GINQ5 & Can a man beat his spouse/partner if he believes she is having sex with another man? & \\
\hline GINQ6 & Is it more important for a boy to get an education than a girl? & \\
\hline \multicolumn{2}{|c|}{ Psychological intimate partner violence assessment scale (PsIPVQ) } & \multirow{14}{*}{$\begin{array}{l}\text { Psychological IPV } \\
\text { (PsIPVQI5) }\end{array}$} \\
\hline PsIPVQI & Is/was he jealous or angry if you (talk/talked) to other men? & \\
\hline PsIPVQ2 & Has he (insists/insisted) on knowing where you (are/were) at all time? & \\
\hline PsIPVQ3 & $\begin{array}{l}\text { Have you ever been insulted by your husband using abusive language that made } \\
\text { you feel bad about yourself? }\end{array}$ & \\
\hline PsIPVQ4 & $\begin{array}{l}\text { Have you ever been threatened by your husband with an object such as a stick, belt, } \\
\text { knife, gun, or other type of weapon, etc? }\end{array}$ & \\
\hline PsIPVQ5 & $\begin{array}{l}\text { Have you ever been created financial hardship/not trust you by your husband to } \\
\text { making money available to you? }\end{array}$ & \\
\hline PsIPVQ6 & Have you ever been frightened your husband by looking angrily at you? & \\
\hline PsIPVQ7 & Have you ever expressed suspicion/accused him that he is unfaithful to you? & \\
\hline PsIPVQ8 & Have you ever been ignored or shown indifference by your husband? & \\
\hline PsIPVQ9 & Have you ever been deprived from privileges in the family by your husband? & \\
\hline PsIPVQI0 & Have you ever been denied by your husband on your basic personal needs? & \\
\hline PsIPVQII & $\begin{array}{l}\text { Have you ever been intentionally not involved by your husband on } \\
\text { decision-making in the family? }\end{array}$ & \\
\hline PsIPVQ12 & Has he belittled or humiliated you in front of other people? & \\
\hline $\begin{array}{l}\text { PsIPVQI3 } \\
\text { PsIPVQI4 }\end{array}$ & $\begin{array}{l}\text { Has he done things to scare or intimidate you on purpose? } \\
\text { Have you ever been restricted by your husband from going to your parent's } \\
\text { home or other places like friends'/relatives' house, places of worship, etc? }\end{array}$ & \\
\hline
\end{tabular}

(Continued) 
Table I (Continued)

\begin{tabular}{|c|c|c|}
\hline & Items & Outcome \\
\hline \multicolumn{2}{|c|}{ Physical intimate partner violence assessment scale (PhIPVQ) } & \multirow{7}{*}{$\begin{array}{l}\text { Physical IPV } \\
\text { (PhIPVQ7) }\end{array}$} \\
\hline PhIPVQI & Has he pushed or shoved you, shaken you, or thrown something at you? & \\
\hline PhIPVQ2 & $\begin{array}{l}\text { Has he punched or hit you with his fist, or twisted your arm or with something that } \\
\text { could hurt you? }\end{array}$ & \\
\hline PhIPVQ3 & Has he slapped, kicked, dragged, or beaten you? & \\
\hline PhIPVQ4 & Has he attacked you with a knife, gun, or other type of weapon? & \\
\hline PhIPVQ5 & Have you ever been scalded or burnt purposefully by your husband? & \\
\hline PhIPVQ6 & Has he choked at you that may disgracing you? & \\
\hline \multicolumn{2}{|c|}{ Sexual intimate partner violence assessment scale (SIPVQ) } & \multirow{5}{*}{$\begin{array}{c}\text { Sexual IPV } \\
\text { (SIPVQ5) }\end{array}$} \\
\hline SIPVQI & $\begin{array}{l}\text { Have you ever been physically forced by your husband to have sex when you did } \\
\text { not want to? }\end{array}$ & \\
\hline SIPVQ2 & Have you ever been intentionally denied or avoided sex by your husband? & \\
\hline SIPVQ3 & $\begin{array}{l}\text { Did you ever have sexual intercourse when you didn't want because you were afraid } \\
\text { of what he might do? }\end{array}$ & \\
\hline SIPVQ4 & Has he forced you to do something sexual that you found degrading or humiliating? & \\
\hline \multicolumn{2}{|c|}{ Husbands can beat their wives if they have justifiable reasons (JWBQ) } & \multirow{6}{*}{$\begin{array}{l}\text { Women's accepting } \\
\text { attitude of justified } \\
\text { wife beating } \\
\text { (JWBQ6) }\end{array}$} \\
\hline JWBQI & If wife goes out without informing her husband? & \\
\hline JWBQ2 & If wife neglects the children? & \\
\hline JWBQ3 & If wife argues with her husband? & \\
\hline JWBQ4 & If wife burns the food? & \\
\hline JWBQ5 & If wife refuses to have sex with him? & \\
\hline
\end{tabular}

EpiData 3.1.0 and exported to SPSS 23.0 for further analysis. The frequency, percentage, mean, and standard deviations were computed for the participants' sociodemographic characteristics. To examine the reliability of the tool to assess domestic VAW, the following analyses were performed: mean, standard deviation, scale mean if item deleted, scale variance if item deleted, corrected item total correlation, and Cronbach's alpha if item deleted.

\section{Results}

The overall response rate of the survey was $95.9 \%$ $(1,217 / 1,269)$. The reasons for non-response were described in detail in Figure 1. The mean age of the women was 30.0 $( \pm 7.1)$ years. The majority of women $(98.8 \%, n=1,202)$ were formally married. Slightly more than half $(52.5 \%, n=639)$ of the women were rural residents. The mean of women's marital duration was $11.5( \pm 7.9)$ years. Furthermore, the mean age of their husbands was $37.3( \pm 9.3)$ years. About one-quarter $(24.9 \%, n=303)$ were unable to read and write. About half $(50.7 \%, \mathrm{n}=617)$ engaged in trade or income-generating activities. Three-fourth $(75.0 \%, \mathrm{n}=913)$ of the women's husbands had a history of addictive substance misuse. Of these, $99.9 \%$ ( $n=912$ ) of husbands had a history of alcohol consumption.
Almost one-quarter $(26.4 \%, \mathrm{n}=321)$ of the women knew their husbands' earning (Table 2).

\section{Cronbach's alpha estimate of the domestic VAW questions}

Cronbach's alpha is a measure of internal consistency (reliability) of the items in the tool, usually a scale. It shows how closely a set of items are rated as a group. It is expressed as a number between 0 and 1 , the closer it is 1 , the higher the reliability. Internal consistency describes the extent to which all the items in a tool measure the same concept, and hence, it is connected to the inter-relatedness of the items within the tool. ${ }^{44}$ The overall Cronbach's alpha of the tool was higher than the minimum recommended value of 0.70 . The women's decision-making and household resource control autonomy were assessed using 13 items and its mean was $30.2( \pm 5.4)$. The women's accepting attitude of justified wife-beating was assessed using five items with a mean of $10.6( \pm 2.6)$. The women's attitude toward inequitable gender-norms was assessed using seven items with a mean of $11.1( \pm 2.5)$. Cronbach's alpha for the women's decision-making autonomy, women's accepting attitude toward justified wife-beating, and inequitable gender-norm were $0.764,0.894$, and 0.867 , respectively. 
Table 2 Sociodemographic characteristics of women, Northwestern Ethiopia, December, $2017(n=1,217)$

\begin{tabular}{|c|c|c|}
\hline Variables & $\mathbf{n}$ & $\%$ \\
\hline Mean age of women (years) & $30.0( \pm 7.1)$ & \\
\hline \multicolumn{3}{|l|}{ Age of women (years) } \\
\hline$\leq 29$ & 604 & 49.6 \\
\hline$\geqq 30$ & 613 & 50.4 \\
\hline \multicolumn{3}{|l|}{ Relationship status } \\
\hline Formally married & $\mathrm{I}, 202$ & 98.8 \\
\hline Cohabitating & 15 & 1.2 \\
\hline \multicolumn{3}{|l|}{ Residence of women } \\
\hline Rural & 639 & 52.5 \\
\hline Urban & 578 & 47.5 \\
\hline \multicolumn{3}{|l|}{ Marital duration of women (years) } \\
\hline$<10$ & 665 & 54.6 \\
\hline$>10$ & 552 & 45.4 \\
\hline \multicolumn{3}{|l|}{ Educational status of women } \\
\hline Illiterate & 621 & 51.0 \\
\hline Able to read and write & 152 & 12.5 \\
\hline $\mathrm{I}-6$ grades & 168 & 13.8 \\
\hline $7-12$ grades & 216 & 17.7 \\
\hline $12+$ & 60 & 4.9 \\
\hline \multicolumn{3}{|l|}{ Occupational status of women } \\
\hline Housewife/farmer & $\mathrm{I}, 037$ & 85.2 \\
\hline Trade/business & 125 & 10.3 \\
\hline Employee (government/NGOs) & 55 & 4.5 \\
\hline \multicolumn{3}{|l|}{ Pregnancy last 12 months $(I, 160)$} \\
\hline Yes & 287 & 24.7 \\
\hline No & 873 & 75.3 \\
\hline \multicolumn{3}{|l|}{ Number of children alive } \\
\hline 0 & 201 & 16.5 \\
\hline$\leqq 2$ & 460 & 37.8 \\
\hline$>2$ & 556 & 45.7 \\
\hline Age of husband (years) & $37.3( \pm 9.3)$ & \\
\hline \multicolumn{3}{|l|}{ Age of husband (years) } \\
\hline$\leq 36$ & 637 & 52.9 \\
\hline$>36$ & 568 & 47.1 \\
\hline \multicolumn{3}{|l|}{ Educational status of husband } \\
\hline Illiterate & 303 & 24.9 \\
\hline Able to read and write & 379 & 31.1 \\
\hline I-6 grades & 222 & 18.2 \\
\hline $7-12$ grades & 227 & 18.7 \\
\hline $12+$ & 86 & 7.1 \\
\hline \multicolumn{3}{|l|}{ Occupational status of husband } \\
\hline Trade/business & 617 & 50.7 \\
\hline Farmer & 489 & 40.2 \\
\hline Employee (government/NGOs) & 111 & 9.1 \\
\hline \multicolumn{3}{|l|}{ Do you know your husband earnings } \\
\hline Yes & 321 & 26.4 \\
\hline No & 896 & 73.6 \\
\hline \multicolumn{3}{|c|}{ Husbands' substance use (mainly alcohol) } \\
\hline Yes & 913 & 75.0 \\
\hline No & 304 & 25.0 \\
\hline
\end{tabular}

Abbreviation: NGO, nongovernmental organization.
In addition, physical domestic VAW was assessed using seven items, and the mean was $12.9( \pm 1.8)$. Psychological domestic VAW was assessed using a tool with 15 items with the mean of the scale analysis of items being $27.1( \pm 4.0)$. Sexual domestic VAW was assessed using a five-item questionnaire with the mean of the scale analysis of items being $9.2( \pm 1.3)$. The Cronbach's alphas for physical, psychological, and sexual domestic VAW assessment questions were $0.876,0.925$, and 0.812 , respectively. The overall Cronbach's alpha of the domestic VAW assessment tool was 0.785 (Table 3).

\section{Discussion}

This reliability analysis estimated the consistency of response from the adapted structured questionnaire(s) that were used to assess domestic VAW. Generally, the adapted survey tool had Cronbach's alpha score of 0.785 , higher than the recommended minimum of 0.70 . Specifically, Cronbach's alphas were women's decision-making autonomy (13 items, 0.764); women's accepting attitude of justified wife-beating (five items with 0.894); physical violence (seven items, 0.876); psychological violence (15 items, 0.925); sexual violence (five items, 0.812); and gender inequitable norm (seven items, 0.867). This tool had a Cronbach's alpha consistent with other studies with a range of $0.68-0.80,{ }^{39}$ higher than $0.80,{ }^{40}$ and greater than $0.90 .{ }^{41}$ Furthermore, this finding is similar to that of a study conducted in Sweden which showed that the Cronbach's alpha of the VAW assessment tool was higher than the minimum recommended value $(>0.70) .{ }^{42}$

In addition, the Cronbach's alpha of the tool is also consistent with the tools used to assess the risk of domestic VAW in China which indicated a Cronbach's alpha of $0.76{ }^{43,44}$ However, this study finding is a bit lower than a study conducted in the USA to assess VAW which showed that Cronbach's alpha of $0.96 .{ }^{45}$ Nevertheless, this finding shows a relatively higher reliability than a study conducted on measurement tool used for physician assessment which has a Cronbach's alpha of $>0.65 .{ }^{46}$ There are some arguments behind the value of Cronbach's alpha. It is argued that it is a coefficient of the reliability or internal consistency of the items, but not a statistical test. ${ }^{44}$ In addition, a high value for alpha does not imply that the measure is unidimensional.

The study's finding can motivate researchers to adopt this consistent tool, which would have a great implication on the analysis of data to inform evidence-based decision-making. This is important since concrete evidence on the level of domestic VAW to understand the problem is needed to help make appropriate decisions. Therefore, this tool can be used by researchers, policy makers, clinicians, and other key stakeholders in sub-Saharan 
Table 3 Item characteristics, item-total correlation, and alpha if item-deleted of the different types of domestic violence against women (VAW) assessment items $(n=I, 217)$

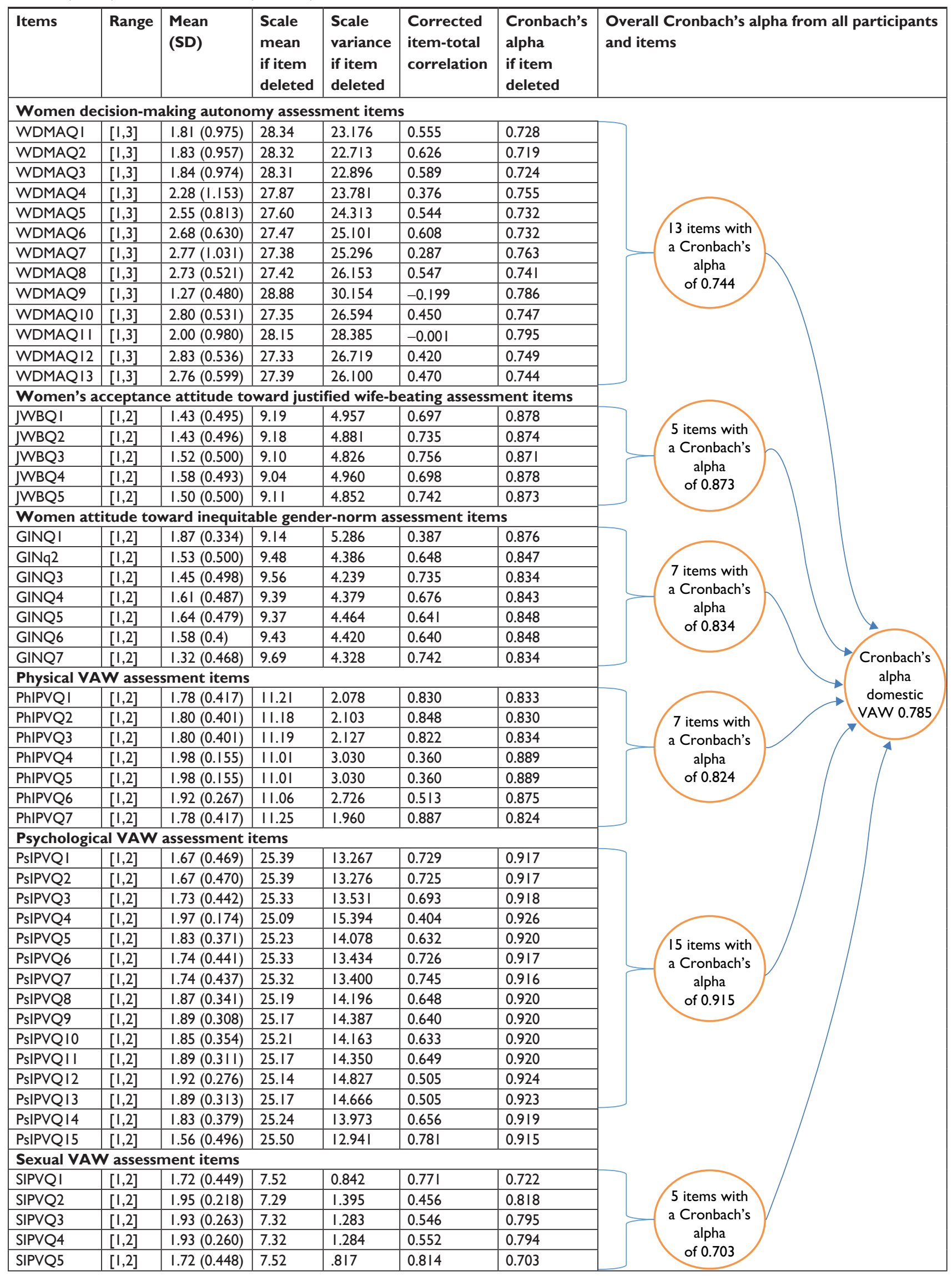


Africa and other low-income settings to enhance studies on domestic VAW. It can also be used for need assessments, program implementation monitoring, and impact evaluations.

\section{Strengths and limitations}

This study has notable strengths including it being community-based, urban-rural mix of sample, well-defined study participants, and representative sample size that can allow for generalization of findings to the general community. However, this study also has some limitations. The disclosure of domestic VAW issues can be a sensitive private issue kept as family secret in most instances. This may be affected by social desirability bias. In addition, some women may suffer from recall bias, unable to remember some of the domestic VAW experiences that they may have accepted as a part of marital life. So social desirability and recall biases may result in underreporting of domestic VAW by the study participants.

\section{Conclusion}

The adapted tool used to assess domestic VAW in Ethiopia had high reliability. Therefore, the researcher can adapt the tool for future studies. Furthermore, assessment of the reliability of the tool in other settings is recommended to confirm its applicability as a tool for low-income countries to determine the level of domestic VAW.

\section{Availability of data and materials}

The data that support the findings are available upon submitting a reasonable request to the corresponding author.

\section{Acknowledgment}

We thank Tropical Disease Research/WHO, University of Ghana, and study participants.

\section{Author contributions}

AS, KT, AM, and AA conceived and designed the study. AS carried out activities from inception to the draft of the manuscript. AS, KT, AM, NA, and AA extensively reviewed the manuscript. All authors contributed to data analysis, drafting and revising the article, gave final approval of the version to be published, and agree to be accountable for all aspects of the work.

\section{Disclosure}

The authors report no conflicts of interest in this work.

\section{References}

1. WHO [webpage on the Internet]. Addressing violence against women and achieving the Millennium Development Goals. Geneva, Switzerland; 2005. Available from: https://www.who.int/gender-equity-rights/ knowledge/who_fch_gwh_05_1/en/. Accessed March 1, 2016.
2. PRB. IGWG. Gender-Based Violence and Reproductive Health \& HIV/ AIDS. Summary of technical update. Washington, DC 200095728;2002. Available from: www.prb.org. Accessed March 1, 2016.

3. USAID, PRB IGWG. Gender-Based Violence: Impediment to Reproductive Health. 2010. Available from: https://www.popline.org/ node/211911. Accessed June 1, 2017.

4. Oxfam. Ending Violence Against Women; An Oxfam Guide. 2012. Available from: https://www.oxfam.org/sites/www.oxfam.org/files/ ending-violence-against-women-oxfam-guide-nov2012.pdf. Accessed November 1, 2015.

5. WHO. Violence Against Women and HIV/AIDS: Critical Intersections Intimate Partner Violence and HIV/AIDS. WHO Bulletin Series. 2004; (1): $1-9$.

6. The World Student Christian Federation and the world YWCA. Domestic Violence Fact Sheet. A 2010 Lenten Study Compiled by the World Council of Churches; 2010. Available from: http://women. overcomingviolence.org. Accessed May 1, 2017.

7. WHO. Global and regional estimates of violence against women: prevalence and health effects of intimate partner violence and non-partner sexual violence. Geneva, Switzerland; 2013. Available from: www. who.int/reproductivehealth. Accessed December 1, 2015.

8. Boldosser-Boesch A, Byrnes D, Carr C, et al. Sexual and Reproductive Health and Rights (SRHR) and the Post- Development Agenda. Brief Cards. 2015. Available from: https:/www.scribd.com/document/235297283/ UAP-SRHR-Post-2015-Briefing-Cards. Accessed June 1, 2016.

9. Ellsberg M, Jansen HAFM, Heise L, Watts CH, García-Moreno C, Study W. Intimate partner violence and women's physical and mental health in the WHO multi-country study on women's health and domestic violence: an observational study. Lancet. 2008;371(9619):1165-1172.

10. Semahegn A, Mengistie B. Domestic violence against women and associated factors in Ethiopia; systematic review. Reprod Health. 2015; 12(1):78.

11. CSA, Central Statistics Agency. Ethiopia Demographic and Health Survey (2011): Central Statistical Agency Addis Ababa, Ethiopia. ICF International Calverton, Maryland, USA; 2012. Available from: https:// dhsprogram.com/pubs/pdf/SR191/SR191.pdf. Accessed October 1, 2015.

12. CSA, Central Statistical agency. Ethiopia Demographic and Health Survey 2016. Addis Ababa, Ethiopia, and Rockville, Maryland, USA: CSA and ICF; 2016. Availbale from: www.ethiodemographyandhealth. org/Measure_DHS_Ethiopia2016.pdf. Accessed June 1, 2017.

13. FDRE, Constitution of the Federal Democratic Republic of Ethiopia Constitution of The Federal Democratic Republic of Ethiopia. Addis Ababa, Ethiopia; 1994. Available from: www.wipo.int/edocs/lexdocs/ laws/en/et/et007en.pdf. Accessed June 1, 2017.

14. FDRE, The Criminal Code of the Federal Democratic Republic of Ethiopia 2004. Proclamation No 414/2004. Addis Ababa, Ethiopia: Federal Democratic Republic of Ethiopia; 2005. Available from: www.wipo. int/edocs/lexdocs/laws/en/et/et011en.pdf. Accessed February 1, 2018.

15. FDRE. The Revised Family Code Proclamation No 213/2000. Addis Ababa, Ethiopia; 2000:96. Available from: hrlibrary.umn.edu/research/ family code (English).pdf. Accessed September 1, 2017.

16. FMOH. Standard Operation procedure for the response and prevention of sexual violence in Ethiopia: Federal Democratic Republic of Ethiopia Ministry of Health. Addis Ababa, Ethiopia; 2016.

17. Tavakol M, Dennick R. Making sense of Cronbach's alpha. Int J Med Educ. 2011;2:53-55.

18. Idre [webpage on the Internet]. What does Cronbach's alpha mean? Institute for Digital Research and Education, UCLA; 2018. Available from: https://stats.idre.ucla.edu/spss/faq/what-does-cronbachsalpha-mean/. Accessed June 1, 2018.

19. Biresaw A. Awi zone health department annual report of the population with in the zonal administration catchments on June 30th, 2018. Zonal reproductive health team leader (received via phone call). Injibara, Ethiopia; 2018.

20. Semahegn A, Belachew T, Abdulahi M. Domestic violence and its predictors among married women in reproductive age in Fagitalekoma Woreda, Awi zone, Amhara regional state, North Western Ethiopia. Reprod Health. 2013;10(1):63. 
21. Zhong B. How to Calculate Sample Size in Randomized Controlled Trial? J Thorac Dis 2009. 2009;1(1):51-54.

22. Semahegn A, Torpey K, Manu A, Assefa N, Ankomah A. Community based intervention to prevent domestic violence against women in the reproductive age in northwestern Ethiopia: a protocol for quasiexperimental study. Reprod Health. 2017;14(1):155.

23. World Medical Association (WMA). World Medical association Declaration of Helsinki ethical principles for medical research involving human subjects, 5th (Edinburgh) Amendment and note of clarification. JAMA. 2013;310(20):2191-2194.

24. Nguyen PH, Nguyen SV, Nguyen MQ, et al. The association and a potential pathway between gender-based violence and induced abortion in Thai Nguyen Province, Vietnam. Glob Health Action. 2012;5(19006):11.

25. Abebe Abate B, Admassu Wossen B, Tilahun Degfie T, Abate BA, Wossen BA, Degfie TT. Determinants of intimate partner violence during pregnancy among married women in Abay Chomen district, Western Ethiopia: a community based cross sectional study. BMC Womens Health. 2016;16(1):16.

26. Rahman M, Nakamura K, Seino K, Kizuki M. Does gender inequity increase the risk of intimate partner violence among women? Evidence from a national Bangladeshi sample. PLoS One. 2013;8(12): e82423.

27. Sapkota D, Bhattarai S, Baral D, Pokharel PK. Domestic violence and its associated factors among married women of a village Development Committee of rural Nepal. BMC Res Notes. 2016;9(1):178.

28. Lamichhane P, Puri M, Tamang J, Dulal B. Women's status and violence against young married women in rural Nepal. BMC Womens Health. 2011;11(1):19.

29. Dalal K, Wang S, Svanström L. Intimate partner violence against women in Nepal: an analysis through individual, Empowerment, family and societal level factors. J Res Heal Sci J. 2014;14(4):251-257.

30. Uthman OA, Moradi T, Lawoko S. Are individual and community acceptance and witnessing of intimate partner violence related to its occurrence? Multilevel structural equation model. PLoS One. 2011; 6(12):e27738.

31. Shannon K, Leiter K, Phaladze N, et al. Gender inequity norms are associated with increased male-perpetrated rape and sexual risks for HIV infection in Botswana and Swaziland. PLoS One. 2012;7(1):e28739.

32. Abramsky T, Watts $\mathrm{CH}$, Garcia-Moreno $\mathrm{C}$, et al. What factors are associated with recent intimate partner violence? Findings from the WHO multi-country study on women's health and domestic violence. BMC Public Health. 2011;11(1):109.
33. Ismayilova L. Spousal violence in 5 transitional countries: a populationbased multilevel analysis of individual and contextual factors. $\mathrm{Am} \mathrm{J}$ Public Health. 2015;105(11):e12-e22.

34. Hayati EN, Högberg U, Hakimi M, Ellsberg MC, Emmelin M. Behind the silence of harmony: risk factors for physical and sexual violence among women in rural Indonesia. BMC Womens Health. 2011;11(1):52.

35. Antai D. Traumatic physical health consequences of intimate partner violence against women: what is the role of community-level factors? BMC Womens Health. 2011;11(1):56.

36. Uthman OA, Lawoko S, Moradi T. Factors associated with attitudes towards intimate partner violence against women: a comparative analysis of 17 sub-Saharan countries. BMC Int Health Hum Rights. 2009; 9(1):14.

37. Conroy AA. Gender, power, and intimate partner violence: a study on couples from rural Malawi. J Interpers Violence. 2014;29(5):866-888.

38. Heise LL. Violence against women: an integrated, ecological framework. Violence Against Women. 1998;4(3):262-290.

39. Ellsberg M, Heise L. Researching Violence against Women; A Practical Guide for Researchers and Activists. Washington DC, United States: World Health Organization and PATH; 2005:259.

40. Emami A, Safipour J. Constructing a questionnaire for assessment of awareness and acceptance of diversity in healthcare institutions. $B M C$ Health Serv Res. 2013;13(1):145.

41. Jenkinson C, Coulter A, Wright L. Short form 36 (SF36) health survey questionnaire: normative data for adults of working age. BMJ. 1993; 306(6890):1437-1440.

42. Shakil A, Donald S, Sinacore JM, Krepcho M. Validation of the hits domestic violence screening tool with males. Fam Med. 2005;37(3): 193-198.

43. Svalin K, Mellgren C, Levander MT, Levander S. The inter-rater reliability of violence risk assessment tools used by police employees in Swedish police settings. Nord Polit. 2017;4(1):9-28.

44. Chan KL. Predicting the risk of intimate partner violence: the Chinese risk assessment tool for victims. J Fam Violence. 2012;27(2):157-164.

45. Chan KL. Assessing the risk of intimate partner violence in the Chinese Population: The Chinese Risk Assessment Tool for Perpetrator Assessing the Risk of Intimate Partner Violence in the Chinese Population: The Chinese Risk Assessment Tool for Perpetrator (CRAT). Violence Against Women. 2014;20(5):500-516.

46. Dienemann J, Glass N, Hanson G, Lunsford K. The domestic violence survivor assessment (DVSA): a tool for individual counseling with women experiencing intimate partner violence. Issues Ment Health Nurs. 2007;28(8):913-925.
International Journal of Women's Health

\section{Publish your work in this journal}

The International Journal of Women's Health is an international, peerreviewed open-access journal publishing original research, reports, editorials, reviews and commentaries on all aspects of women's healthcare including gynecology, obstetrics, and breast cancer. The manuscript management system is completely online and includes

\section{Dovepress}

a very quick and fair peer-review system, which is all easy to use. Visit http://www.dovepress.com/testimonials.php to read real quotes from published authors. 